\title{
Clinical profile of women seeking medical termination of pregnancy at a tertiary care institute, South India
}

\author{
Pratima Agarwal, Papa Dasari* \\ Department of Obstetrics and Gynecology, JIPMER, Puducherry, India \\ Received: 08 February 2021 \\ Revised: 13 March 2021 \\ Accepted: 15 March 2021 \\ *Correspondence: \\ Dr. Papa Dasari, \\ E-mail: dasaripapa@gmail.com \\ Copyright: (c) the author(s), publisher and licensee Medip Academy. This is an open-access article distributed under \\ the terms of the Creative Commons Attribution Non-Commercial License, which permits unrestricted non-commercial \\ use, distribution, and reproduction in any medium, provided the original work is properly cited.
}

\begin{abstract}
Background: Medical termination of pregnancy (MTP) has largely become a medical procedure rather than surgical and in the recent times and few women approach public health care facility and hence the profile of women has changed and is different in various hospitals. Hence this study was undertaken with the objectives to know the proportion of indications as per MTP act and gestational age in women who opted MTP. The study also aimed to find out the clinic-demographic profile and the method of MTP and contraception adopted along with MTP.

Methods: A retrospective cohort over 3 year period (2016-2019). Data was extracted from the medical records of women who were hospitalised for MTP and analysed for the outcome parameters Viz: Women were categorised as per the indication for MTP. In each category of indication, age, socioeconomic status, trimester of MTP, number of living children, methods of MTP and methods of contraception adopted was noted. The results were expressed as proportions and frequencies and the trend over 3 years was expressed as percentage per total number of deliveries per year.

Results: There were 640 MTPs over 3 year period and this constituted $1.22 \%$ of total deliveries (52,555). Fifty one percent were first trimester MTPs. Thirty eight percent were done for congenital malformations, $32 \%$ for socioeconomic reasons of family limitation, $17 \%$ for saving physical or mental health , $4 \%$ for rape victims and $8 \%$ for failure of contraception. The mean age was 28 years and the age in humanitarian group was $\leq 20$ years. More than $88 \%$ belonged to lower socioeconomic class and $37 \%$ were third gravidae with 2 living children. Medical methods were used in $90 \%$ of terminations and $46 \%$ adopted contraception.

Conclusions: The most common reason for opting MTP is congenital malformation of fetus. Women who achieved the desired family size and non-practice of contraception was the next common indication for termination of pregnancy and majority of terminations in this group were first trimester. Practice of contraception to avoid unwanted pregnancy and measures to prevent congenital malformations are essential to reduce medical termination of pregnancies.
\end{abstract}

Keywords: Contraception, MTP, Medical abortion, Trend

\section{INTRODUCTION}

MTP Act was introduced in 1972 with aim of reducing maternal mortality and surgical methods were used initially. Since the introduction of medical abortion methods and their easy availability over the counter the profile of women seeking Medical Termination of
Pregnancy (MTP) at health care facility has changed for the past two decades. ${ }^{1}$ The methods of first trimester as well as second trimester terminations have become entirely medical. ${ }^{2}$ With more advancements in early diagnosis of pregnancy and availability of ultrasonography the indications for medical terminations and the gestational age at the time of termination also has 
undergone a sea change. In this context, we aimed to analyse the profile of pregnant women who sought MTP at our Institute for the past three years. The objectives were to find out the proportions of the indications for MTP as per the MTP act and the trend over 3 years, to find out the proportion of women who underwent first trimester MTP as per the indication, to analyse the clinical profile of women seeking MTP with respect to age, socioeconomic status, gravidity and parity and number of living children and to report on methods used for MTP.

\section{METHODS}

This was a retrospective cohort study undertaken from July 2016 to June 2019 (3 year period) at JIPMER, Puducherry, South India, after obtaining necessary permissions. The records were retrieved from Medical Record Section of JIPMER with the help of the data stored in the department of Obstetrics and Gynaecology (MTP Register). All women who were admitted for MTP during this period were included for analysis of demographic and clinical data. Women who deferred to undergo MTP or absconded were excluded from methods for termination of pregnancy.

Data collection included age, socioeconomic status, gravidity, parity, number of living children, gestational age at seeking termination and indication for termination and methods of termination. The indications were grouped as per MTP Act 1 in to 5 groups Viz: 1: To save physical and mental health of pregnant women which included medical and surgical and mental disorders complicating pregnancy. 2: Eugenic or Congenital fetal malformations, which included life threatening congenital malformations in single or multiple. 3: Humanatarian reasons, mainly pregnancy arising out of rape and unwed pregnancies. 4: Socieo-economic reasons such as unplanned pregnancy, not using contraception and for family limitation. 5: Failure of contraceptive methods which resulted in intra-uterine pregnancy. Methods of contraception adopted along with MTP was also noted.

Descriptive statistics were used to analyse the data and it was expressed as percentages and proportions and the trend over 3 years was determined.

\section{RESULTS}

There were 640 women who opted for MTP over the 3 year period and this constituted $1.22 \%$ of total deliveries. There is no difference in the trend among 3 years. The most common indication was Congenital anomaly (38\%) followed by unplanned pregnancy (32\%). MTP was adviced to save physical and mental health of pregnant women in $17.3 \%$. MTP for humanitarian grounds was necessary in $4.3 \%$ and for failure of contraception in $8 \%$ (Table 1). Table 2 shows the trimester of pregnancy at MTP. First trimester MTPs constituted 51\% and second trimester $49 \%$. First trimester MTP was done in $36 \%$ of humanitarian reasons, $86 \%$ of unplanned pregnancies, and $84 \%$ of failed contraception. Only $5.3 \%$ of women with congenital malformations and $76 \%$ for saving physical and mental health opted MTP in first trimester.

Table 1: Indications for MTP and trend over 3 years.

\begin{tabular}{|c|c|c|c|c|}
\hline \multirow[t]{2}{*}{ Parameter } & $\begin{array}{l}\text { July 2016- } \\
\text { June } 2017\end{array}$ & $\begin{array}{l}\text { July 2017- } \\
\text { June } 2018\end{array}$ & $\begin{array}{l}\text { July 2018- } \\
\text { June } 2019\end{array}$ & Total \\
\hline & $\mathbf{N}(\%)$ & $\mathbf{N}(\%)$ & $\mathbf{N}(\%)$ & $\mathbf{N}(\%)$ \\
\hline Total number of deliveries & $\mathbf{1 5 , 5 3 7}$ & 17,451 & 19,567 & 52,555 \\
\hline Total MTPs & $195(1.26)$ & $212(1.21)$ & $233(1.19)$ & $640(1.22)$ \\
\hline \multicolumn{5}{|l|}{ Indications as per MTP Act } \\
\hline $\begin{array}{l}\text { To save physical and mental health of pregnant } \\
\text { women }\end{array}$ & $28(14.5)$ & $38(18)$ & $45(19.3)$ & $111(17.34)$ \\
\hline Eugenic/Congenital anomalies & $68(34.9)$ & $81(28.2)$ & $96(41.2)$ & $245(38.28)$ \\
\hline Humanitarian/unmarried/pregnancy after rape & $10(5.12)$ & $9(4.2)$ & $9(3.9)$ & $28(4.36)$ \\
\hline $\begin{array}{l}\text { Socio-economic -unwanted child/not used } \\
\text { contraception }\end{array}$ & $72(36.9)$ & $66(31)$ & $67(27.6)$ & $205(32.03)$ \\
\hline Failure of contraceptives & $17(8.7)$ & $18(8.5)$ & $16(6.9)$ & $51(7.99)$ \\
\hline
\end{tabular}

Table 2: Indications for MTP and trimester of pregnancy.

\begin{tabular}{|lll|}
\hline Indication as per MTP Act & First Trimester MTP & Second trimester MTP \\
\hline To save physical and mental health $(\mathbf{n = 1 1 1})$ & $\mathbf{N}(\boldsymbol{\%})$ & $\mathbf{N}(\boldsymbol{\%})$ \\
\hline Eugenic congenital anomalies $(\mathbf{n = 2 4 5 )}$ & $84(75.6)$ & $27(24.4)$ \\
\hline Humanatarian $(\mathbf{n}=\mathbf{2 8})$ & $13(5.3)$ & $232(94.7)$ \\
\hline Socio-economic reasons $(\mathbf{n = 2 0 5 )}$ & $10(35.7)$ & $18(64.3)$ \\
\hline Failure of contraception $(\mathbf{n = 5 1 )}$ & $178(85.6)$ & $27(13.4)$ \\
\hline Total $(\mathbf{6 4 0})$ & $43(84.3)$ & $8(15.7)$ \\
\hline
\end{tabular}


Table 3: Clinical profile of women who opted for MTP.

\begin{tabular}{|c|c|c|c|c|c|c|}
\hline & $\begin{array}{l}\text { To save } \\
\text { physical and } \\
\text { mental health }\end{array}$ & $\begin{array}{l}\text { Eugenic } \\
\text { /congenital } \\
\text { anomalies }\end{array}$ & Humanitarian & Socioeconomic & $\begin{array}{l}\text { Failure of } \\
\text { contraception }\end{array}$ & Total \\
\hline Characteristic & $\mathrm{n}=111$ & $n=245$ & Unmarried & $\begin{array}{l}\text { Reasons (not } \\
\text { used } \\
\text { contraception) }\end{array}$ & $\mathrm{n}=\mathbf{5 1}$ & $\mathbf{N}(\%)$ \\
\hline & & & $n=28$ & $n=205$ & & $640(100)$ \\
\hline \multicolumn{7}{|c|}{ Age (Mean age)- 28 years (Range $: 12-48$ years) } \\
\hline$\leq \mathbf{2 0}$ & $2(1.8)$ & $33(13.47)$ & $16(57)$ & - & $1(2)$ & $52(8.1)$ \\
\hline 21-25 & $28(25)$ & $101(41.22)$ & $10(35.7)$ & $38(18.5)$ & $10(19.6)$ & $187(29.2)$ \\
\hline $26-30$ & $42(39)$ & $81(33.06)$ & $2(7)$ & $77(37.5)$ & $22(43)$ & $224(35)$ \\
\hline 31-35 & $34(31)$ & $24(9.79)$ & - & $58(28.3)$ & $13(25.5)$ & $129(20)$ \\
\hline$\geq 36$ & $5(4.5)$ & $6(2.45)$ & - & $32(15.6)$ & $5(9.8)$ & $48(7.5)$ \\
\hline \multicolumn{7}{|c|}{ Socio-economic status } \\
\hline Lower & $95(85.6)$ & $232(94.6)$ & $17(60.7)$ & $184(89.7)$ & $41(80.4)$ & $569(88.9)$ \\
\hline Middle & $11(9.9)$ & $11(4.48)$ & $8(28.6)$ & $17(8.3)$ & $8(15.6)$ & $55(8.59)$ \\
\hline Upper & $5(4.5)$ & $2(0.8)$ & $3(10.7)$ & $4(2)$ & $2(3.9)$ & $16(2.4)$ \\
\hline \multicolumn{7}{|l|}{ Religion } \\
\hline Christian & $4(3.6)$ & $6(2.45)$ & $3(10.7)$ & $11(5.3)$ & $3(5.8)$ & $27(4.22)$ \\
\hline Hindu & $100(90)$ & $232(94.6)$ & $25(89)$ & $189(92)$ & $47(92)$ & $593(92.66)$ \\
\hline Muslim & $7(6.3)$ & $7(2.86)$ & - & $5(2.4)$ & $1(2)$ & $20(3.1)$ \\
\hline \multicolumn{7}{|c|}{ Gravidity (Obstetric score) } \\
\hline Primigravida & $13(11.7)$ & $105(42.86)$ & - & - & 0 & $118(18.4)$ \\
\hline Gravida-2 & $36(32.4)$ & $73(29.79)$ & - & $10(0.5)$ & $10(19.6)$ & $129(20)$ \\
\hline Gravida-3 & $39(35)$ & $44(17.96)$ & - & $128(62.4)$ & $30(58.8)$ & $241(37.6)$ \\
\hline Gravida-4 & $15(13.5)$ & $13(5.31)$ & - & $50(24.4)$ & $7(13.7)$ & $85(13.2)$ \\
\hline$\geq$ Gravida 5 & $8(7.2)$ & $10(4.08)$ & - & $17(8.3)$ & $4(7.8)$ & $39(6)$ \\
\hline \multicolumn{7}{|c|}{ Number of living children } \\
\hline 1 & $45(40.5)$ & $86(35)$ & - & $13(6.3)$ & $10(19.6)$ & $154(24)$ \\
\hline 2 & $35(31.5)$ & $21(8.5)$ & - & $159(77.5)$ & $34(66.6)$ & $249(38.9)$ \\
\hline 3 & $7(6.3)$ & $3(1.2)$ & - & $30(14.6)$ & $5(9.8)$ & $45(7)$ \\
\hline$\geq 4$ & $3(2.7)$ & - & - & 3 & $2(3.9)$ & $08(1.3)$ \\
\hline
\end{tabular}

Second trimester MTP was most commonly opted for $94.7 \%$ of eugenic/ congenital malformations, $64 \%$ of humanitarian reasons and $24 \%$ for saving physical and mental health of pregnant women.

Table 3 shows the clinical and socio-demographic characteristics of women who opted for MTP. The mean age was 28 years and the range was $12-48$ years. The most common age group was 26 to 30 years. Ninety percent belonged to lower socioeconomic status and majority (93\%) were Hindus. The most common obstetric status of women seeking MTP was a third gravida followed by second gravida. The main reason to seek MTP for a primigravidae was congenital malformation (42.8\%) and the main reason for a multi gravida was unplanned pregnancy. Forty percent had two living children and $24 \%$ had only one live child at the time of MTP.

\section{To save mental and physical health}

The characteristics included young women (64\%) and middle aged women (35.5\%). Majority belonged to lower socioeconomic status. Thirty five percent were third gravidae and $32 \%$ second gravidae. Majority had one to two children.

\section{Eugenic /congenital malformations}

This indication was present in 245 women. Majority $43 \%$ were primigravidae and $35 \%$ had one live child and $95 \%$ belonged to lower socio-economic status.

\section{Humanatrian grounds/unmarried}

Majority $(57 \%)$ were $<20$ years of age and $11 \%$ belonged to Upper Socio-economic status. 


\section{Socio-economic reasons/not practiced contraception}

Majority were young women between 20-26 years and $90 \%$ belonged to lower socioeconomic status. Sixty two percent were second gravidae and $77 \%$ had two living children.

\section{Failure of contraception}

The women belonged to 26-35 years of age and $80 \%$ belonged to lower socioeconomic status. Twenty percent were second gravidae and $59 \%$ were third gravidae and $67 \%$ had two living children.

The methods of contraceptive failure is shown in Table 4. Tubectomy failure and condom failure constituted 31\% each. Failure of CU-T and OCP constituted $11 \%$ and 5\% respectively.

Table 4: Type of contraception practiced.

\begin{tabular}{|ll|}
\hline $\begin{array}{l}\text { Type of contraception } \\
\text { practiced }\end{array}$ & $\begin{array}{l}\text { Number of failures } \\
(\mathbf{n = 5 1 )}\end{array}$ \\
\hline Tubectomy & $20(30.9 \%)$ \\
\hline IUCD & $6(11.7 \%)$ \\
\hline OCP & $3(5.8 \%)$ \\
\hline Condom & $20(30.9 \%)$ \\
\hline Emergency contraception & $2(3.9 \%)$ \\
\hline
\end{tabular}

The indications for MTP under category to save mental and Physical health is shown in Table 5. The most common reason was cardiovascular disease (41\%) followed by autoimmune disorder (17\%) and Endocrine cause such as Graves's disease and uncontrolled diabetes in early pregnancy. Seven percent were on chemotherapy or radiotherapy. HIV or AIDS constituted another $7 \%$.

Table 6 shows the actual number who underwent MTP and adoption of contraception. Approximately 5\% of women who opted for MTP initially deferred later and some absconded without reasons. Of the 609 women, who underwent MTP, $46 \%$ adopted contraception and $54 \%$ underwent only MTP. Majority who adopted contraception belonged group of unplanned pregnancy or socioeconomic reasons $(82 \%)$ and to failed contraception group $(80 \%)$. Majority of those who sought MTP only belonged to the group of Eugenic or congenital malformation group and humanitarian grounds.

Table 5: To save physical and mental health.

\begin{tabular}{|lll|}
\hline \multirow{2}{*}{ System affected } & Number & Percentage \\
\hline Cardiovascular system & 46 & 41.4 \\
\hline Renal system & 11 & 9.9 \\
\hline CNS & 3 & 2.7 \\
\hline Liver disorder & 2 & 1.8 \\
\hline $\begin{array}{l}\text { Autoimmune/hereditary } \\
\text { disorders }\end{array}$ & 19 & 17.1 \\
\hline Endocrine & 12 & 10.8 \\
\hline $\begin{array}{l}\text { On chemotherapy/ } \\
\text { radiotherapy }\end{array}$ & 8 & 7.2 \\
\hline Malignancy & 6 & \\
\hline Non-malignant & 2 & 1.8 \\
\hline $\begin{array}{l}\text { CNS and musculoskeletal } \\
\text { tuberculosis }\end{array}$ & 2 & 7.2 \\
\hline HIV/AIDS & 8 & \\
\hline
\end{tabular}

Table 6: Contraception adopted with MTP.

\begin{tabular}{|llllllll|}
\hline $\begin{array}{l}\text { Indication as per MTP } \\
\text { Act }\end{array}$ & $\begin{array}{l}\text { Deferred/ } \\
\text { absconded } \\
\text { N }(\%)\end{array}$ & $\begin{array}{l}\text { Total } \\
\text { MTP(N) }\end{array}$ & $\begin{array}{l}\text { Under- } \\
\text { went } \\
\text { MTP only } \\
\text { N }(\%)\end{array}$ & Sterilisation & CU-T & $\begin{array}{l}\text { Hormonal } \\
\text { With } \\
\text { contraception }\end{array}$ \\
\hline $\begin{array}{l}\text { To save physical and } \\
\text { mental health pregnant } \\
\text { women (n=111) }\end{array}$ & $7(6.3)$ & 104 & $36(34.6)$ & 42 & 20 & 6 & $68(65.4)$ \\
\hline $\begin{array}{l}\text { Eugenic Congenital } \\
\text { anomalies (n=245) }\end{array}$ & $5(2)$ & 240 & $225(93)$ & 11 & 4 & - & $15(6.25)$ \\
\hline $\begin{array}{l}\text { Humanatarian/ } \\
\text { Unmarried (n=28) }\end{array}$ & $6(21)$ & 22 & $21(95.4)$ & - & - & 1 & $1(3.5)$ \\
\hline $\begin{array}{l}\text { Socio-economic reasons } \\
\text { (n=205) }\end{array}$ & $11(5.3)$ & 194 & $35(17)$ & $137(70.6)$ & 16 & 6 & $159(81.96)$ \\
\hline $\begin{array}{l}\text { Failure of } \\
\text { contraception (n=51) }\end{array}$ & $2(3.9)$ & 49 & $10(20.41)$ & 36 & 2 & 1 & $39(79.59)$ \\
\hline Total (640) & $31(4.8)$ & 609 & $327(54)^{*}$ & $226(37)^{*}$ & 42 & 14 & $282(46)^{*}$ \\
\hline
\end{tabular}

*percentage calculated out of 609 
Table 7: Methods of MTP.

\begin{tabular}{|c|c|c|c|c|c|}
\hline \multirow{3}{*}{ Trimester of pregnancy } & \multicolumn{5}{|c|}{ Methods of MTP } \\
\hline & \multicolumn{2}{|c|}{ Medical methods N (\%) } & \multicolumn{2}{|c|}{ Surgical methods $\mathbf{N}(\%)$} & \multirow{2}{*}{$\begin{array}{l}\begin{array}{l}\text { Combined } \\
\text { (medical+ } \\
\text { surgical method) }\end{array} \\
\mathbf{N}(\%)\end{array}$} \\
\hline & $\begin{array}{l}\text { Mifepristone } \\
+ \text { Misoprostal }\end{array}$ & $\begin{array}{l}\text { Extra- } \\
\text { amniotic } \\
\text { instillations }\end{array}$ & $\begin{array}{l}\text { Suction } \\
\text { evacuation }\end{array}$ & Hysterotomy* & \\
\hline First trimester $(n=315)(52 \%)$ & $126(40)$ & $5(1.6)$ & $30(9.5)$ & - & $154(48.9)$ \\
\hline Second trimester $(n=294)(48 \%)$ & $138(46.9)$ & $120(40.8)$ & - & $1 *(0.40)$ & 35 (11.9) \\
\hline Total (609) & $264(43.34)$ & $125(20.5)$ & $30(4.9)$ & 1 & $189(31)$ \\
\hline
\end{tabular}

Hysrerotomy was necessary in one woman. She was 35 years G3P2L1 with previous 2LSCS and overt diabetic admitted at 18 weeks +6 days of pregnancy with large abdominopelvic cyst in fetus. Failure of medical methods Viz: Foley+extra-amniotic saline instillation followed by oxytocin and single dose of Mifepristone $200 \mathrm{mg}$ and Misoprostol $25 \mathrm{mg}$ combination (Table 7).

Table 7 shows the methods of MTP in 609 women. More than $90 \%$ of first trimester MTP were by medical methods and only $9.5 \%$ were by suction evacuation because of contraindications for misoprostal and previous caesarean section. Forty nine percent required surgical interference in the form of curettage to remove retained products of conception to achieve complete abortion. All second trimester MTP were medical and only one woman required hysterotomy due to failed medical method because of previous 2 caesarean sections. There were no other complications

\section{DISCUSSION}

The indications for medical termination of pregnancy are clearly spelt in the MTP act and all health care facilities follow the same with guidelines including the consent procedure and confidentiality. The act provides instructions for safe, affordable, accessible abortion services to pregnant women to terminate pregnancy under certain circumstances. ${ }^{1}$ It was estimated that 15.6 million abortions occurred in India in 2015 and only $22 \%$ were in hospital setting or health facility. ${ }^{2}$ Hence this study reflects one face of abortions in health facility. The trend in incidence over the 3 year period did not change and stood at $1.2 \%$ of all deliveries.

The commonest reason for opting MTP in this study was for congenitally malformed fetus which is encouraging. The reason may be that these were mostly second trimester abortions in which congenital malformation could be diagnosed and sometimes multidisciplinary advice from neonatologists and paediatric surgeons and geneticists was necessary for decision making Extensive counselling regarding termination or continuing pregnancy would have been necessary. The next common reason for opting MTP was unplanned or unintended pregnancy $(32 \%)$ which is a discouraging issue as these women were multiparous and had not practiced contraception despite having more than 2 living children. The rate of unintended pregnancy was estimated to be 70.1 per 1000 pregnancies which is high. ${ }^{2}$ In the study undertaken by Veena et al from South India the commonest reason for seeking MTP was reported to be contraceptive failure (50\%) whereas this accounted for only $8 \%$ in the current study. ${ }^{3}$ Four percent of MTPs were undertaken for humanitarian indication in the current study and it was only $0.7 \%$ in the study of Veena and collegues. Socioeconomic reason was the commonest indication (40\%) in women seeking MTP in the study published by Shankarraiah et al from Karnataka. ${ }^{4}$

Over all, the rate of second trimester MTP was $49 \%$ and first trimester MTP was $51 \%$. The main reasons or indications for second trimester MTP was contributed by Congenital malformations (Eugenic), humanitarian grounds followed by - to save physical and mental health. This spectrum may remain for few decades as most congenital malformations could be diagnosed in second trimester only as the fetus develops, and as the pregnancy advances the health of women with medical disorders may worsen and all the unmarried pregnant women seek abortion later than first trimester due to social reasons and unawareness of diagnosing pregnancy early.

The mean age of women was 28 years, and the most common age group was $\leq 20$ years $(57 \%)$ of those with humanitarian reasons, 21- 25 years for eugenic reasons, 26-35 years for unplanned pregnancy and failure of contraception. The age groups are important when one plans counselling and interventions for various target groups for prevention of unplanned pregnancies and to prevent congenital malformations. We could not find any study which analysed as per various groups of indications. The study from Tamil Nadu, South India reported $72 \%$ to be below 30 years of age and $92 \%$ were first trimester abortions and main reason was for social reason for completion of the family. ${ }^{5}$ In the current study the mean age was 28 years and the main reason was congenital malformation and hence $49 \%$ were second trimester abortions but among those who completed the family $85.6 \%$ were first trimester terminations. This 
shows that women were able to diagnose pregnancy early and seeking abortion services appropriately.

Though high resolution Ultrasound machines are available congenital malformations are mostly diagnosed in the second trimester as various organ systems differentiate during second trimester after organogenesis of first trimester. Becker and Wegner reported that $84 \%$ of anomalies could be diagnosed accurately at 11-14 weeks scan but other reports found accurate diagnosis to be possible mostly during second trimester. ${ }^{6-8}$ It was estimated that globally 27,000 newborn deaths occurred within 28 days after birth due to congenital malformations and in India approximately $6 \%$ of births were reported to have congenital malformations. ${ }^{9}$ Decision making for continuation of pregnancy or termination depends on the lethality of the anomaly and most lethal anomalies are only terminated. Though most lethal anomalies could be diagnosed by 20 weeks of pregnancy so as to undertake termination of pregnancy as per MTP act, a recent study in India reported their incidence after 24 weeks of pregnancy to be 51.75/10,000 pregnanies $(0.5 \%) .{ }^{10}$ Of late high incidence of congenital malformations are reported in India with a pregnancy termination rate of 4.39 per 1000 births. $^{11}$

The decision to terminate pregnancy under the category to save physical and mental health of pregnant woman is multidisciplinary often involving physician opinion regarding affect of continuation of pregnancy on medical or mental illness and vice-versa. This decision has to be a shared one keeping the individual characteristics of the patient. ${ }^{12}$ This was the reason in $23 \%$ of women who underwent MTP in the study by Veena et al, involving 555 women. $^{3}$ In the current study this indication constituted $17 \%$.

World wide, MTP for social reasons of limiting family is undertaken in 14 countries having $20 \%$ of World's population and without restrictions in 56 countries with $40 \%$ of World's population. ${ }^{13}$ This is the most common indications for undertaking MTP. ${ }^{6,14}$ The abortion (MTP) ratio was found to be least for first pregnancy order and highest for the third. ${ }^{14}$ The current study also found maximum women who underwent MTP for social reasons were third gravidae with two living children. Women who underwent MTP for social reasons adopted permanent method of contraception $(87.5 \%)$ and this is higher when compared to the current study $(70 \%){ }^{5}$ The reasons may be sociocultural like preference for having a male child which is not explored in this study. This was addressed in the article published by Radheshyam et al. ${ }^{14}$

MTP for contraceptive failure accounted for $50 \%, 11.6 \%$ and $3.1 \%$ and in the current study it was $8 \% .^{3-5}$ These differences are mainly due to social determinants of the population seeking care at health care facility. The commonest reason for failure of contraception in the current study was tubectomy failure and the other studies have not explored the reasons for the same. The compensation being awarded by the Government may be one of the reasons why these women sought care in our Institute apart from for undergoing re-sterilisation. Among the contraceptive failures condom failure was the second commonest reason $(31 \%)$. A study from North India reported the main reason for seeking MTP as contraceptive failure $(83.2 \%)$ and most common method cited the method was condom failure. ${ }^{15}$ Yet another study from Maharashtra reported contraceptive failure in $99.1 \%$ as reason for undergoing MTP. ${ }^{16}$ In the indication of humanitarian grounds all the 28 subjects were rape victims in this study and majority were second trimester pregnancies. No one was denied of abortion services though it is reported that the rape victims suffer denial of safe abortion in public sectors in India due to misinterpretation of MTP Act rules and regulations. ${ }^{17}$

Methods of termination of pregnancy have largely become medical and in the current study more than $90 \%$ were medical abortions. Manual Vacuum aspiration (surgical method) was used in $62.5 \%$ of MTPs undertaken in the study by Veena et al. ${ }^{3}$ A systematic review on the late first trimester medical abortion reported a success rate of $78-90 \%$ and offers evidence that these medication can be administered in set up of home without any side effects. ${ }^{18}$ It was estimated that $81 \%$ of MTPs were by medication undertaken in the health care facilities or at home and only $14 \%$ were surgical. ${ }^{2}$ Hysterotomy was done in 5 women in the study of Veena et al involving 555 pregnancies and in our study only one women required it to be done. The adoption of concurrent contraception depends on the indication and the number of living children and the acceptance of contraception was high among those who completed the family and this is similar with other studies. ${ }^{3-5}$ Oral contraception was the choice of contraception in most women in North India where as tubectomy or CU-T in South India. . $^{3,16}$

\section{CONCLUSION}

MTP accounted for $1.2 \%$ of all deliveries and the trend remained the same over 3 year period. The most common reason for opting MTP was for termination of a congenitally malformed fetus followed by non - practice of contraception or unplanned pregnancy even after completion of the family. Overall majority were second trimester terminations as the bulk was made by congenital malformation group but most of the unplanned pregnancy terminations occurred in the first trimester which is encouraging. MTP was necessary in $17 \%$ to save physical and mental health of women. Most of the women belonged to lower socioeconomic status. More than $75 \%$ of women with failed contraception and those pregnant despite achieving desired family size (nonpractice of contraception) adopted contraception along with MTP and majority adopted permanent method. The method of MTP practiced in our Institute is by medical methods and these were safe without any complications. Health education regarding prevention of congenital 
malformations and adoption of contraception are the need of the hour to reduce the number of medical terminations of pregnancy.

\section{Limitations}

Retrospective nature of the study and hence the preventive factors for MTP could not be analysed especially for the Socio-economic group and also preconceptional care for medical disorders complicating and necessitating MTP.

\section{Funding: No funding sources}

Conflict of interest: None declared

Ethical approval: The study was approved by the Institutional Ethics Committee

\section{REFERENCES}

1. The Medical Termination of Pregnancy Act 1971. Ministry of Health and Family Welfare India. Available at tcw.nic.in > Acts , MTP-Act-1971. Accessed on 12 November 2020.

2. Singh S, Shekar C, Acharya R, Moore A, Stillman M, Pradhan MR. The incidence of abortion and unintended pregnancy in India, 2015. The Lancet. 2018;8:e111-20.

3. Veena L, Sarojini. A review of medical termination of pregnancy profile in a tertiary care center. Int $\mathrm{J}$ Reprod Contracept Obstet Gynecol. 2017;6:3332-7.

4. Shankaraiah RH, Annadani RR, Vijayashankar V, Undi M. Medical termination of pregnancy and subsequent adoption of contraception. Int J Reprod Contracept Obstet Gynecol. 2013;2(3):367-71.

5. Maheswari UR, Jayanthi TP. Abortion seeking behaviour: a study from tertiary care hospital. Int $\mathbf{J}$ Community Med Public Health. 2017;4:2303-7.

6. Becker R, Wegner RD. Detailed screening for fetal anomalies and cardiac defects at the 11 - 13-week scan. Ultrasound Obstet Gynecol. 2006;27:613-8.

7. Kashyap N, Pradhan M, Singh N, Yadav S. Early detection of fetal malformation, a long distance yet to Cover! Present status and potential of first trimester Ultrasonography in detection of fetal congenital malformation in a developing country: Experience in a tertiary care Centre in India. Journal of Pregnancy. 2015:623059.
8. Lavanya S, Seethalakshmi V. A two-year study of patterns and prevalence of congenital malformations. Int J Reprod Contracept Obstet Gynecol. 2018;7:114-8.

9. Congenital anomalies (birth defects) Diagnosis and Management. Available at https:// www. aimu.us/2016/12/05/congenital-anomalies-birthdefects. Accessed on 12 November 2020.

10. Tiwari P, Gupta MM. Study of lethal congenital malformations at a tertiary-care referral centre in North India. Cureus, 2020;12(4):e7502.

11. Bhide P, Gund P, Kar A. Prevalence of congenital anomalies in an indian maternal cohort: healthcare, prevention, and surveillance implications. PLoS One. 2016;11(11):e0166408.

12. Kalra S, Ganie MA, Unnikrishnan AG. Overt hypothyroidism in pregnancy: can we consider medical termination of pregnancy? Indian J Endocrinol Metab. 2013;17(2):197-9.

13. Borgatta L, Stubblefield P. Induced abortion: Indications, Counselling and services. Glob Libr. 2009;10:38-43.

14. Bairagi R, Effects of sex preference on contraceptive use, abortion and fertility in Matlab, Bangladesh. Int Family Planning Per. 2001;27(3):137-43.

15. Sharma B, Saxena N, Sharma A, Arora N. Epidemiology of MTP in a tertiary care centre over a period of 3 years. Int $\mathrm{J}$ Reprod Contracept Obstet Gynecol. 2017;6(11):4918-22.

16. Senapati J, Samel DR, Paradkar D, Patil AN. Medical termination of pregnancy: six years study of the trend and profile of the clients in a Metropolitan Public hospital. JEBMH. 2018;8(15):1282-86.

17. Deosthali BP, Rege S. Denial of safe abortion to survivors of rape in India. Health Hum Rights. 2019;21(2):189-98.

18. Kapp N, Eckersberger E, Lavelanet A, Rodriguez MI. Medical abortion in the late first trimester: a systematic review. Contraception. 2019;99(2):77-86.

Cite this article as: Agarwal $\mathrm{P}$, Dasari P. Clinical profile of women seeking medical termination of pregnancy at a tertiary care institute, South India. Int J Reprod Contracept Obstet Gynecol 2021;10:1580-6. 